\title{
Trends and factors associated with dengue mortality and fatality in Brazil
}

\author{
Enny Santos Paixão ${ }^{[1]}$, Maria da Conceição Nascimento Costa[1], \\ Laura Cunha Rodrigues ${ }^{[2]}$, Davide Rasella ${ }^{[1]}$, Luciana Lobato Cardim ${ }^{[1]}$, \\ Alcione Cunha Brasileiro ${ }^{[1]}$ and Maria Gloria Lima Cruz Teixeira ${ }^{[1]}$
}

[1]. Instituto de Saúde Coletiva, Universidade Federal da Bahia, Salvador, Bahia, Brasil. [2] London School of Hygiene and Tropical Medicine, London, United Kingdom.

\begin{abstract}
Introduction: Studies that generate information that may reduce the dengue death risk are essential. This study analyzed time trends and risk factors for dengue mortality and fatality in Brazil from 2001 to 2011. Methods: Time trends for dengue mortality and fatality rates were analyzed using simple linear regression. Associations between the dengue mortality and the case fatality rates and socioeconomic, demographic, and health care indicators at the municipality level were analyzed using negative binomial regression. Results: The dengue hemorrhagic fever case fatality rate increased in Brazil from 2001 to 2011 ( $\beta=0.67 ; p=0.036$ ), in patients aged $0-14$ years $(\beta=0.48 ; p=0.030)$ and in those aged $\geq 15$ years $(\beta=1.1 ; p<0.01)$. Factors associated with the dengue case fatality rate were the average income per capita $(M R R=0.99 ; \mathrm{p}=0.038)$ and the number of basic health units per population $(\mathrm{MRR}=0.89 ; \mathrm{p}<0.001)$. Mortality rates increased from 2001 to $2011(\beta=0.350 ; \mathrm{p}=0.002)$.Factors associated with mortality were inequality $(\mathrm{RR}=1.02 ; \mathrm{p}=0.001)$ high income per capita $(\mathrm{MRR}=0.99 ; \mathrm{p}=0.005)$, and higher proportions of populations living in urban areas $(\mathrm{MRR}=1.01 ; \mathrm{p}<0.001)$. Conclusions: The increases in the dengue mortality and case fatality rates and the associated socioeconomic and health care factors, suggest the need for structural and intersectoral investments to improve living conditions and to sustainably reduce these outcomes.
\end{abstract}

Keywords: Dengue. Mortality. Fatality. Trend. Social determinants.

\section{INTRODUCTION}

Globally, dengue is the most important arboviral disease, because the incidence of infections has increased in recent decades, it has a wide geographic spread, and it can progress to serious and lethal forms; it has been prominently placed among the world's major health problems ${ }^{(1)}$.

The first dengue epidemics associated with deaths were reported in the Americas in 1980, and, since then, the numbers of dengue-related deaths have increased continuously ${ }^{(2)}$. During the first decade of the $21^{\text {st }}$ century, half of the dengue related deaths in South America occurred in Brazil ${ }^{(3)}$. Until 2006, and unlike dengue in Southeast Asia, this viruses was more common in adults in Brazil. In 2007, a marked shift in its age distribution had occurred, and it mostly affected children, among whom there was a higher incidence of severe cases ${ }^{(4)}$. This shift in the age

Corresponding author: Msc. Enny Santos da Paixão. Instituto de Saúde Coletiva/UFBA. Rua Basilio da Gama s/n, Canela, 40110-040 Salvador, Bahia, Brasil.

Phone: 5571 3336-0695; Mobile: 5571 9647-5619

e-mail: npaixaoenfo@yahoo.com.br

Received 4 May 2015

Accepted 23 June 2015 distribution reversed in 2010, when dengue cases predominately occurred among those who were aged over 15 years ${ }^{(5)}$. Despite these trends and shifts, few studies have investigated the mortality or case fatality rates, or changes in the age profiles of dengue patients.

Since 2007, the number of dengue - related deaths in Brazil has gradually increased, with the mortality rate increasing from $0.01 / 100,000$ people in 2000 to $0.4 / 100,000$ people in 2010, when the dengue hemorrhagic fever (DHF) case fatality rate reached $12 \%$, which was the highest rate recorded in this decade ${ }^{(5)}$. Among the Latin American countries, Brazil has made the greatest effort to control dengue fever (DF) and reduce its fatal outcomes ${ }^{(6)}$. Between 2001 and 2005, the cost of dengue to Brazil was estimated at US\$322 million, with approximately $3 \%$ of this amount spent on deaths, which, on average, led to the loss of 1,391.68 years of potential life $\mathrm{e}^{(7)}$. Despite recent advances in Brazil's health care system, problems remain that must be tackled. Specifically, social position strongly influences access to use and quality of health care services ${ }^{(8)(9)}$.

An investigation involving Latin American and Caribbean countries highlighted the roles of biological, contextual, and environmental factors in the increasing severity of dengue ${ }^{(10)}$. Studies that generate information that may contribute to reducing the risk of death from this disease and that assists health systems to address the demands posed by this disease are essential. This study aimed to analyze the temporal evolution of 
dengue mortality and the DHF case fatality rate, and to identify the factors associated with the mortality and the case fatality rates in Brazil from 2000 to 2011.

\section{METHODS}

\section{Study design}

Two different analyses were carried out in this study. First, time series analyses of dengue (DF + DHF) mortality and DHF fatalities were undertaken for Brazil as a country and for the regions, from 2000 to 2011, in which the years were used as the units of analysis. Secondly, a cross-sectional ecological study of the spatial aggregates was under taken to analyze the risk factors for dengue (DF + DHF) mortality and fatality for the period from 2008 to 2011 that used the municipalities as the units of analysis.

\section{Data sources}

Information about dengue fever and DHF deaths was gathered from the Mortality Information System [Sistema de Informação sobre Mortalidade (SIM) - Dados do Sistema Único de Saúde (DATASUS)], and deaths classified under the codes $A 90$ and $A 91$ using the $10^{\text {th }}$ Revision of the International Classification of Diseases (ICD)-10 were considered.

Information about dengue fever and DHF cases was gathered from the Notifiable Diseases Information System [Sistema de Informação sobre Agravos de Notificação (SINAN) - DATASUS].

The National Register of Health Facilities (Cadastro Nacional de Estabelecimentos de Saúde) was used to determine the number of health units.

Staff from the Brazilian Institute of Geography and Statistics [Instituto Brasileiro de Geografia e Estatística (IBGE)] determined the population numbers and the socioeconomic indicators for each municipality and year.

\section{Outcomes definitions}

For the trends, the dengue mortality rate was defined as the number of dengue deaths, which included deaths from DHF and dengue fever, from SIM, divided by the population numbers from IBGE, for each year and municipality from 2000 to 2011. The DHF fatality rate was defined as the number of DHF deaths from SIM divided by the DHF case numbers from SINAN, for each year and municipality from 2001 to 2011 .

For the risk factor analysis, The dengue mortality rate was defined as the sum of the number of deaths caused by dengue, which included DHF and dengue fever deaths, from SIM from 2008 to 2011, divided by the sum of the population from IBGE from 2008 to 2011 . The dengue case fatality rate was defined as the sum of the number of deaths caused by dengue, which included DHF and dengue fever deaths, from SIM from 2008 to 2011, divided by the sum of the number of cases of dengue from SINAN during the same period.

We used different case fatality indicators to estimate the trends and risk factors, because we used the same formula as the Brazilian Ministry of Health to estimate the case fatality rate, which was the numbers of DHF deaths divided by the notified DHF cases, to facilitate comparisons with other studies. However, for the analysis of the risk factors, information may have been lost if the denominator comprised notified DHF cases only, because the municipalities only notify DHF cases when all the criteria established by the World Health Organization in 1997 are met $^{(11)}$. Therefore, deaths from DHF may have been attributed to dengue fever.

\section{Temporal trend analysis}

The annual case fatality rates, including the overall rates and those for people aged 0-14 years and $\geq 15$ years, for DHF and the dengue mortality rates (per 100,000 inhabitants) between 2000 and 2011 for Brazil and the large geographic regions within Brazil were plotted on graphs and their fluctuations analyzed. The trends were estimated using simple linear regression analysis and the calendar year as the independent variable. This regression analysis generates a $\beta$ coefficient; hence, for each year we would expect a specific unit increase (positive $\beta$ ) or decrease (negative $\beta$ ) in the dengue mortality or DHF fatality rates. Autocorrelation was evaluated using the Durbin-Watson statistic, and when a value that was $>2$ determined it was present, the Prais-Winsten method was applied to treat self-correlated residuals ${ }^{(12)}$.

\section{Analysis of associated factors}

All of the Brazilian municipalities that reported at least one dengue case between 2008 and 2011 were included in this study. These years were selected because $74 \%$ of all recorded deaths from dengue were concentrated with in this period.

Mean (annual) dengue mortality and fatality rates from 2008 to 2011 were used to smooth the effects of epidemics and distortions that resulted from small numbers of dengue -related deaths.

The health care variables analyzed, namely, the numbers of basic health units per 1,000 inhabitants, the numbers of hospital beds per 1,000 inhabitants, and the numbers of physicians per 1,000 inhabitants, were the mean values for the four years considered in this analysis. The socioeconomic and demographic variables included the Gini index, which measured the inequality of the income distribution within the population (where a value of $0 \%$ represents perfect equality and a value of $100 \%$ implies perfect inequality), the average income per capita, the percentage of the population that was living in urban households with a garbage collection service (\% urbanization rate) that was determined as the percentage of the population living in urban areas compared with the total population, and the illiteracy rate (\%), all of which were collected as part of the Census that gathered data on socioeconomic variables at the municipal level in 2010. These variables were selected based on the literature ${ }^{(13)}$ and on data availability.

As the dependent variables are represented by rates, the regression models that best fitted these distributions were the Poisson and negative binomial regression models ${ }^{(14)}$. However, the Poisson model assumes equality between the mean and the variance, which was not met by these data as they displayed overdispersion. To confirm that the negative binomial regression model provided a better fit for the data, we used the 
Akaike information criterion (AIC) and the Bayesian information criterion (BIC). These criteria supported the use of the negative binomial model. The AIC was used in this modeling approach because it provided the best fit for cross-validation in the larger data sets and it was easier to implement. To control for excess zeros in the distribution of the rates, the zero-inflated negative binomial regression model was tested, and the AIC and BIC statistics were calculated to determine which model had the best fit. Ultimately, the classic negative binomial regression model produced a better fit.

All of the statistical analyses were performed using Stata Statistical Software: Release 10 (Stata Corp LP, College Station, TX, USA).

\section{Ethical considerations}

Although this study used anonymized secondary data at an aggregate level, it was approved by the Ethics Committee of the Public Health Institute of the Federal University of Bahia (Comitê de Ética do Instituto de Saúde Coletiva da Universidade da Federal da Bahia) CAAE: 15103713.1.0000.5030.

\section{RESULTS}

From 2001 to $2011,4,995,546$ dengue cases were reported in Brazil, and, of these, $0.4 \%$ received a diagnosis of DHF or dengue shock syndrome (DSS); there were 3,156 deaths, of which, $60.5 \%$ were classified as being caused by DHF/DSS. The remaining $39.5 \%$ of the deaths were classified as being caused by dengue fever. The Southeast and Northeast regions of Brazil accounted for over $70 \%$ of all fatal cases, while the southern region accounted for less than $2 \%$ of all fatal cases.

\section{Trends in dengue hemorrhagic fever fatality and dengue mortality}

During the period studied, the DHF case fatality rate in Brazil increased by $0.67(\beta)$ per year $(p=0.03)$. The mean value of this indicator was $8.2 \%$, which ranged from $3.5 \%$ in 2001 to $11.8 \%$ in 2011 . These rates were high across Brazil, and they were mainly seen in the North (10.7\%) and Southeast (8.6\%) regions. The lowest rate was in the Central-West region (7.9\%). Figure 1 shows that an upward trend in the fatality rate was observed in all regions, but this trend was only statistically significant in the Southeast region $(\beta=1.17 ; \mathrm{p}=0.03)$.

The DHF case fatality rate was at its highest among individuals aged 15 years or over (average 23.4\%), and especially among those aged 80 years and over. Among those who were younger than 15 years of age, those under 1 year of age experienced notably higher case fatality rates, with a mean rate of $8.2 \%$, which ranged from zero deaths from 2001 to 2004 and in 2006, to $25 \%$ in 2005 . Figure 2 shows that in both age groups, the increases in the DHF case fatality rates were statistically significant $(\beta=1.1 ; \mathrm{p}<0.01$ for those aged 15 years or over, and $\beta=0.48 ; p=0.03$ for those aged $0-14$ years).

The mean annual dengue mortality rate from 2000 to 2011 was $0.14 / 100,000$ inhabitants, which ranged from $0.01 / 100,000$ inhabitants in 2000 to $0.41 / 100,000$ inhabitants in 2010, with peaks observed in 2002 and 2008. The increasing trend for mortality was significant $(\beta=0.02 ; \mathrm{p}=0.001)$. The CentralWest region had the highest dengue mortality rate in 2010 $(1.4 / 100,000$ inhabitants). This region also exhibited the largest upward trend $(\beta=0.077 ; \mathrm{p}=0.01)$, followed by the northern region $(\beta=0.059 ; \mathrm{p}<0.01)$. In the southeastern and northeastern regions, the increase was $0.03 / 100,000$ inhabitants per year $(p<0.05)$. Figure 3 shows that the Southern region recorded the lowest number of deaths (52), the lowest mean mortality rate $(0.01 / 100,000$ inhabitants), and the smallest upward trend $(\beta=0.004, p=0.02)$.

Until 2006, those aged over 15 years had a higher risk of death from dengue (average 0.04/100,000 inhabitants), especially those aged 80 years and older (mean $0.2 / 100,000$ inhabitants). From 2007 to 2009 , those who were younger than 15 years had higher mortality rates $(0.2 / 100,000$ inhabitants), especially in the Northeastern region where this distribution

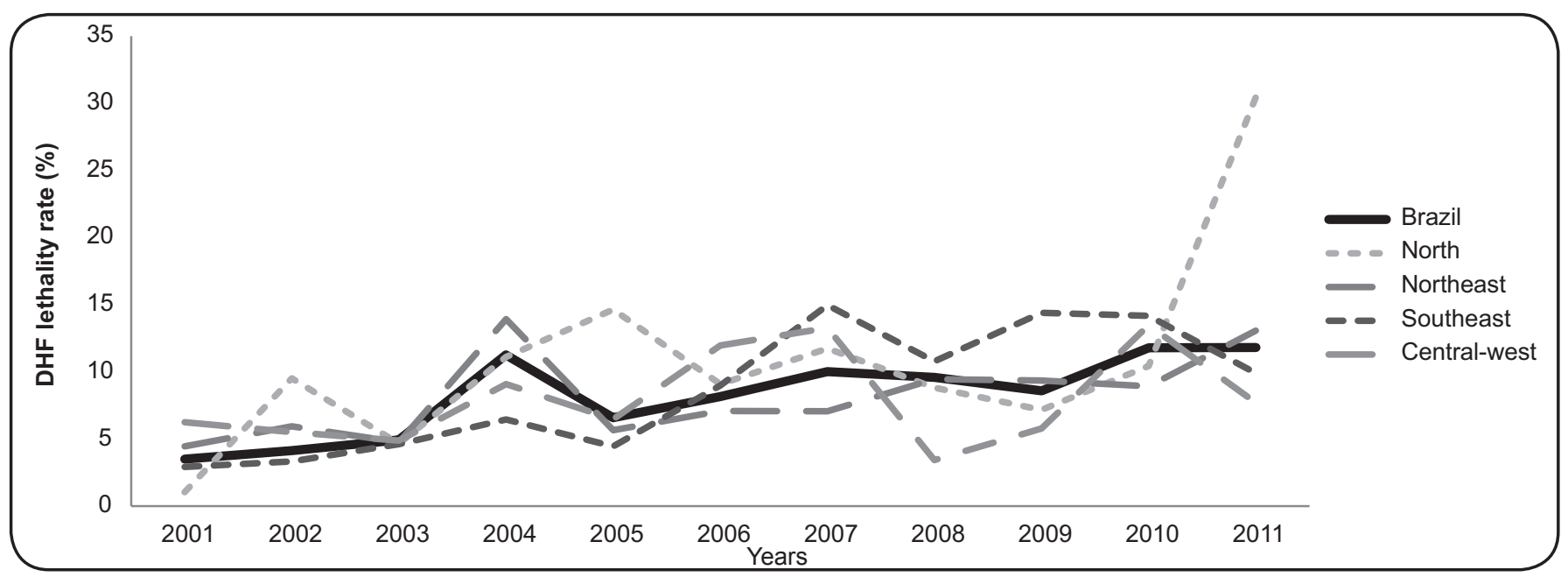

FIGURE1 - Temporal evolution of DHF fatality rates in Brazil and its large regions from 2001 to 2011. DHF: dengue hemorrhagic fever. 


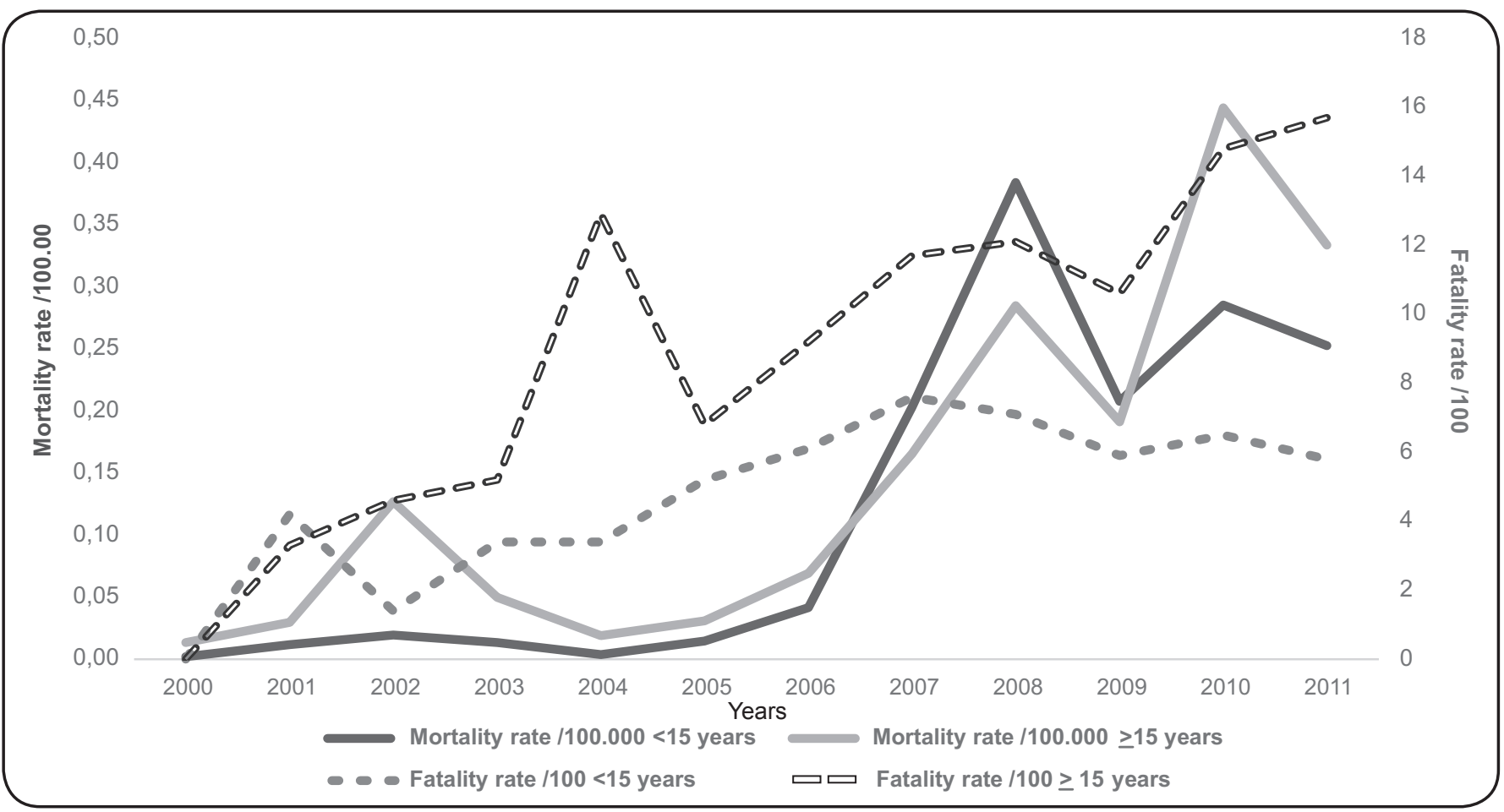

FIGURE 2 - Temporal evolution of dengue mortality and fatality rates in Brazil from 2000 to 2011 according to the study's age groups.

persisted until 2010. In the Southeastern region, this reversal was only observed in 2008. The Central-West and Northern regions showed no substantial changes in the age distributions of the mortality rates. In 2010, this indicator was higher among those aged over 15 years $(0.4 / 100,000$ inhabitants). Within this group, those aged 80 years and older were the most affected by dengue mortality $(2.8 / 100,000$ inhabitants in 2010). For those aged under 15 years, the highest rates of dengue mortality were observed among children during the first year of life. Upward trends in the dengue mortality rates $(\beta=0.03)$ were observed for those who were younger than 15 years $(\mathrm{p}=0.07)$ and for those aged 15 years and over $(\mathrm{p}=0.04)$. In the Figure 2, among those who were younger than 15 years, the dengue mortality peak occurred in 2008, while for those aged 15 years and over the dengue mortality peak occurred in 2010 .

The upward trends in DHF case fatality dengue mortality were maintained when the epidemic years were excluded from the series, excepted the trend for the dengue mortality rate in the southern region became statistically insignificant.

\section{Factors associated with dengue mortality and fatality}

Of the 5,565 Brazilian municipalities, 4,843 reported at least one dengue fever case between 2008 and 2011, and these were included in the analysis of the factors associated with dengue mortality and fatality.

Dengue mortality (Table 1) was statistically associated with the socioeconomic and urbanization indicators; hence, it increased as the Gini index increased or worsened [mortality rate ratio $(M R R)=1.02 ; \mathrm{p}<0.01$, and a $1 \%$ increase in the Gini index determined a $2 \%$ increase in the dengue mortality rate. The MRR increased as the proportion of the population that lived in urban areas increased (MRR $=1.01 ; \mathrm{p}<0.01)$, and as the percentage of the urban population that had garbage collections increased $(\mathrm{MRR}=1.01 ; \mathrm{p}<0.01)$, but it decreased as the income per capita increased $(M R R=0.99 ; \mathrm{p}=0.05)$. Among the variables related to health care, none were statistically significant, but these were retained in the final model because they had been defined apriori based on the theoretical background.

Table 1 shows that the dengue case fatality rate was inversely associated with the average income per capita (MRR $=0.99$; $\mathrm{p}=0.05)$ and with the number of basic health units $(\mathrm{MRR}=0.89$; $\mathrm{p}<0.01)$. Other variables related to health care were not statistically significant, but they were retained in the model because they were defined a priori due to the theoretical background.

\section{DISCUSSION}

The risk of death from dengue in Brazil increased significantly between 2000 and 2011, and this trend was present in all of the regions and in all of the age groups analyzed. In 2011, dengue mortality had increased 39-fold compared with that in 2000, and the DHF case fatality rate had doubled. These findings confirm that the severity of dengue epidemics is increasing in Brazil, as suggested by the reported increase hospitalization rates ${ }^{(15)}$.

In this study, we observed that the goal of reducing the DHF case fatality rate to less than $1 \%$, which was established by the National Dengue Control Program in Brazil(16), was 
TABLE 1 - Mortality rate ratio obtained from multivariate negative binomial regression analysis of the associations between dengue mortality and fatality rates and socioeconomic, demographic, and health care indicators for the municipalities in Brazil that reported at least one case of dengue $(n=4,843)$ from 2008 to 2011 .

\begin{tabular}{|c|c|c|c|c|c|c|}
\hline Indicators & \multicolumn{3}{|c|}{ Mortality rate } & \multicolumn{3}{|c|}{ Fatality rate } \\
\hline Gini index $(\%)$ & 1.02 & $<0.01$ & $1.01-1.04$ & 1.00 & 0.98 & $0.98-1.01$ \\
\hline Urbanization rate $(\%)$ & 1.00 & $<0.01$ & $1.01-1.03$ & 1.00 & 0.19 & $0.99-1.00$ \\
\hline Illiteracy rate $(\%)$ & 1.00 & 0.70 & $0.98-1.01$ & 1.00 & 0.46 & $0.99-1.01$ \\
\hline Average income per capita & 0.99 & 0.05 & $0.99-0.99$ & 0.99 & 0.04 & $0.99-0.99$ \\
\hline Number of hospital beds/1,000 inhabitants & 1.03 & 0.15 & $0.98-1.07$ & 1.01 & 0.40 & $0.97-1.06$ \\
\hline Number of basic health units/1,000 inhabitants. & 0.98 & 0.64 & $0.92-1.04$ & 0.89 & $<0.01$ & $0.84-0.94$ \\
\hline Number of physicians/1,000 inhabitants. & 0.98 & 0.84 & $0,84-1.14$ & 0.98 & 0.85 & $0.86-1.13$ \\
\hline
\end{tabular}

MRR: mortality rate ratio; CI: confidence interval.

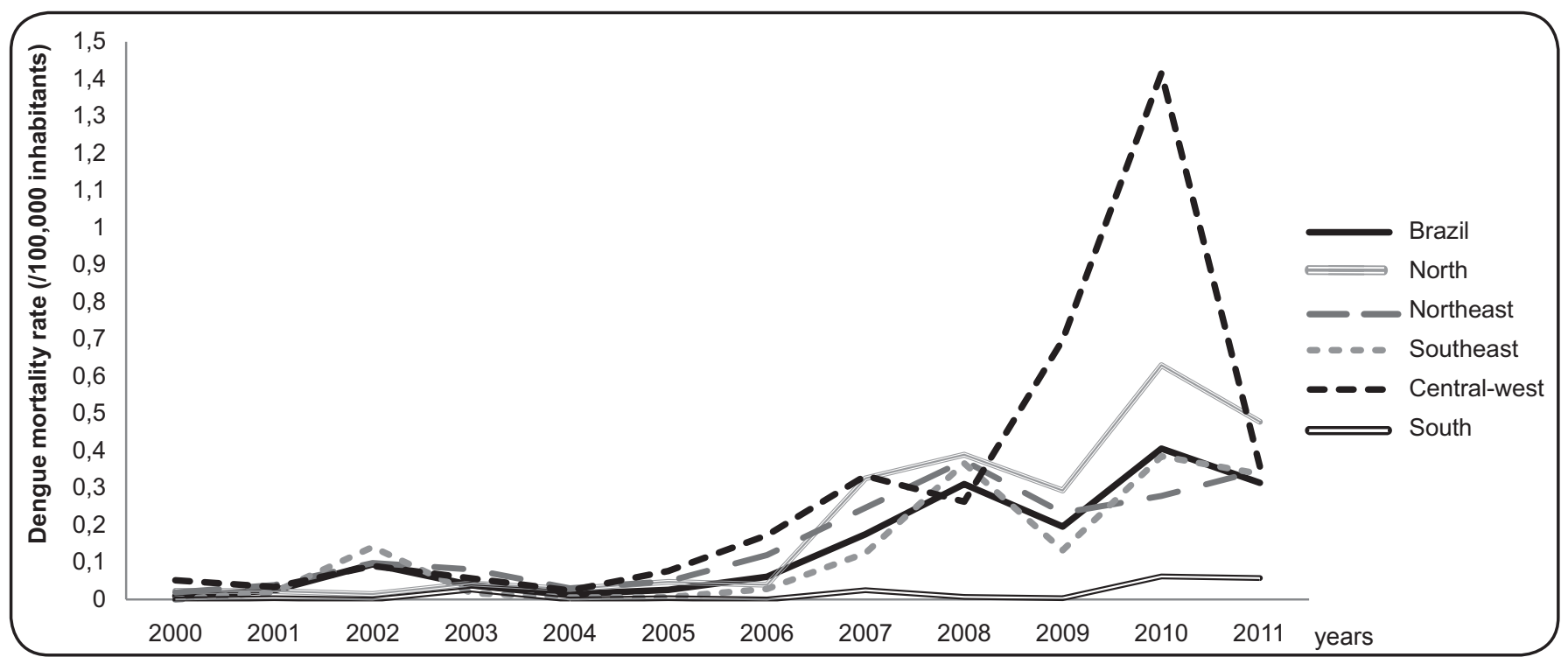

FIGURE 3 - Temporal evolution of dengue mortality rates in Brazil and its large regions from 2001 to 2011.

not reached in any of the years studied. Even in countries such as Singapore, where all suspected dengue patients are admitted for appropriate and timely treatment, the DHF case fatality rates reached $7.1 \%$ and $8.2 \%$ during the 2005 and 2007 epidemics, respectively ${ }^{(17)(18)}$, which are similar to Brazil's mean case fatality rate $(8.2 \%)$. The case fatality indicator is, of course, very sensitive to the choice of denominator. If all cases of dengue are used as the denominator, regardless of their clinical types, the case fatality rate becomes $1 \%$ or less, as observed in Singapore in $2007(0.27 \%)^{(18)}$. In Brazil, the official statistics only used cases that were classified as having DHF as the denominator, which is in contrast to many countries. In addition to overestimating the case fatality rate, this difference complicates comparisons with other countries.
This raises the question of whether the goal of reducing the DHF case fatality rate to less than $1 \%$ is indeed feasible using DHF as the denominator given the current level of therapeutic knowledge.

With respect to the factors that determine the dengue mortality and DHF case fatality rates, the negative association with the average income per capita is a consistent finding. Better socioeconomic and health conditions have been recognized as protective factors against death, particularly from infectious diseases $^{(18)(19)(20)}$. Only the number of primary health care units was associated with lower case fatality rates, which suggests that access to primary care health professionals may reduce the DHF case fatality rate. However, the role of primary care in reducing the risk of death when the disease is present should be investigated more thoroughly. 
Moreover, the quality of the care provided must be a risk factor. The observed absence of associations between lethal outcomes because of dengue and supplies of hospital beds and physicians in the municipalities strengthens this assertion, and is consistent with findings that point to the low-resolution abilities of a significant proportion of Brazilian hospitals ${ }^{(21)}$. However, it is difficult to determine the influence of the quality of medical care from studies that are based on data from death certificates.

The number of primary care units was not associated with dengue mortality. Mortality is a function of the disease incidence and the case fatality rate. The lack of an association with mortality probably reflects the fact that primary health care is unlikely to reduce the incidence of this disease. The association between dengue mortality and the Gini index, which measures social inequality, can be explained by the large social and environmental disparities that exist in the Brazilian municipalities ${ }^{(22)}$, which may contribute to the formation of substandard aggregations that facilitate the spread of dengue ${ }^{(23)(24)}$ and increase the numbers of infected individuals with in these populations. In addition, there is evidence of associations between the Gini index and the prevalence of cardiovascular disease ${ }^{(25)}$ and asthma ${ }^{(26)}$, which are comorbidities that are considered risk factors for death from dengue fever and for more serious forms of dengue ${ }^{(27)(28)(29)(30)}$. No studies have examined the relationship between the Gini index and dengue mortality rates, but investigations in to the spatial distribution of dengue fever incidence have determined that this index is geographically associated ${ }^{(23)}$.

The limitations of this study include the fact that it was conducted using secondary data. Hence, its results may have been underestimated through underreporting and errors regarding the causes of death. These errors may be the consequence of the difficulties associated with diagnosing the disease, which have been highlighted in a study ${ }^{(31)}$ that used the linkage method to compare the SIM and SINAN databases. The unavailability of some indicators, including those associated with the quality of health care, the prevalence of co-morbidities, and the seroprevalence of dengue in the population, represents an obstacle to improving the detection of associations. Moreover, ecological studies that examine the aggregate spaces are subject to the effects of the aggregation of areas, spatial autocorrelations, and the multicollinearities of some of the predictor variables that can alter the effects of each of these factors. Thus, the results should not be extrapolated to individuals, because even though individuals might live in the same city, they will not have equal risks. However, despite this non-equivalence, one must recognize that producing the disease and death involves the mediation of factors that include living conditions that are determined by socioeconomic, environmental, and demographic factors. Therefore, if the target of interest is the population, one should seek to capture the results of these interactions, because this knowledge can be a valuable management tool for more effective decision making within each specific situation.

Ecological studies on dengue fever mortality and living conditions are scarce in the literature, but an interesting investigation involving Latin American and the Caribbean countries revealed the existence of a relationship between dengue fever mortality and socioeconomic indicators ${ }^{(10)}$. Our study was similar to this study, but we analyzed a broader set of dengue fever socioeconomic- and healthcare-related determinants in a country with a uniform notification system and a higher number of units for analysis, and, consequently, our study has a higher statistical power. Moreover, using the municipalities as the unit for analysis rather than the country guarantees a uniform distribution of the variable values within the units and a lower possibility of ecological fallacy-related biases. The magnitude of dengue fever epidemics is increasing ${ }^{(32)}$, and there is a risk that severe forms will continue to occur as this frequency increases. Therefore, while seeking to control dengue fever epidemics, the feasibility of reducing the mortality and case fatality rates represents a particular challenge in the short term.

Our results show that in low-to-middle income countries such as Brazil, efforts to control the negative outcomes associated with dengue fever will require the implementation of structural and intersectoral investments aimed at improving the socioeconomic and living conditions of the population.

\section{CONFLICT OF INTEREST}

The authors declare that there is no conflict of interest.

\section{FINANCIAL SUPPORT}

Thanks to Coordenação de Aperfeiçoamento de Pessoal de Nivel Superior that provided technical support for the development and implementation of this study.

\section{REFERENCES}

1. World Health Organization (WHO). Dengue and severe dengue. Fact sheet $n^{\circ} 117$ (Internet), 2014 (updated 2014 March; cited 2014 July 22). WHO; 2014. (Accessed 2014 September). Available at: http://www.who.int/mediacentre/factsheets/fs117/en/

2. Guzmán MG, Kouri G. Dengue in the American Region. An update, 2002. Lancet Infect Dis 2002; 2:33-42.

3. Pan American Health Organization (PAHO). Dengue hemorrhagic fever (DHF) in the Americas, by Country: number of reported cases of dengue and Figures for 2010 (to week noted by each country. (Internet). PAHO; 2010 (Acessed 2014 August). Available at http://www.paho.org/

4. Teixeira MG. Few characteristics of dengue's fever epidemiology in Brazil. Rev Inst Med Trop São Paulo 2012; 54:1-4.

5. Ministério da Saúde. Sistema de Informação de Agravos de Notificação (Internet). Brasília: Ministério da Saúde. (Acessed 2014 January). Available at http://dtr2004.saude.gov.br/sinanweb/

6. Ministério da Saúde. Análise da situação das doenças transmissíveis no Brasil no período de 2000 a 2010 (Internet). Brasília: Ministério da Saúde. (Acessed 2014 June) Available at: http://portalsaude.saude.gov.br/portalsaude/arquivos/pdf/2013/ Fev/21/saudebrasi12011_parte1_cap3.pdf

7. Suaya JA, Shepard DS, Siqueira JB, Martelli CT, Lum LC, Tan $\mathrm{LH}$, et al. Cost of dengue cases in eight countries in the Americas and Asia: a prospective study. Am J Trop Med Hyg 2009; 80:846-855. 
8. Instituto Brasileiro de Geografia e Estatística (IBGE). Pesquisa Nacional por Amostra de Domicílios: Um panorama da saúde no Brasil. Acesso e utilização de serviços, condições de saúde e fatores de risco e proteção à saúde. Rio de Janeiro: IBGE; 2008 (Accessed 2014 April). Available at http://bvsms.saude.gov.br/bvs/ publicacoes/pnad_panorama_saude_brasil.pdf

9. Pavão AL, Coeli CM, Lopes CS, Faerstein E, Werneck GL, Chor D. Uso de serviços de Saúde segundo a posição socioeconômica em trabalhadores de uma universidade pública. Rev Saude Publica 2012; 46:98-103.

10. Diaz-Quijano FA, Waldman EA. Factors associated with dengue mortality in Latin America and the Caribben, 1995-2009: An Ecological study. Am J Trop Med Hyg 2012; 86:328-334.

11. World Health Organization (WHO). Dengue hemorrhagic fever: Diagnosis, Treatment, Prevention and Control. Geneva: WHO; 1997.

12. Bruin J. Newtest: command to compute new test. UCLA: Academic Technology Services, Statistical Consulting Group. (Accessed 2014 July). Available at: http://www.ats.ucla.edu/stat/ stata/ado/analysis/

13. Instituto Brasileiro de Geografia e Estatística (IBGE). Censo demográfico 2010. Características da População e dos domicílios. Rio de Janeiro: IBGE; 2010. (Accessed 2014 June). Available at: http://www.ibge.gov.br/home/estatistica/populacao/censo2010/ caracteristicas_da_populacao/default_caracteristicas_da_ populacao.shtm

14. Hilbe JM. Negative binomial regression. New York: Cambrige University Press, USA; 2011.

15. Costa MCN, Barreto FR, Coelho, G, Teixeira MG. Change in the epidemiologic pattem in occurrence of dengue and dengue hemorragic fever in Brazil. J Epidemiol Community Health 2011: 65:A361.

16. Fundação Nacional de Saúde (FUNASA). Programa Nacional de Controle da Dengue (PNCD). Brasília: FUNASA; 2002.

17. Koh BK, Ng LC, Kita Y, Tang CS, Ang LW, Wong KY, et al. The 2005 dengue epidemic in Singapore: epidemiology, prevention and control. Ann Academy Med 2008; 37:538-545.

18. Ler TS, Ang LW, Yap GSL, Ng LC, Tai JC, Jamesb L, et al. Epidemiological characteristics of the 2005 and 2007 dengue epidemics in Singapore - similarities and distinctions. WPSAR 2011; 2:24-29.

19. Nguyen K-H, Jimenez-Soto E, Dayal P, Hodge A. Disparities in child mortality trends: what is the evidence from disadvantaged states in India? the case of Orissa and Madhya Pradesh. Int J Equity Health 2003; 12:45.
20. Tusting LS, Willey B, Lucas H, Thompson J, Kafy HT, Smith R, et al. Socioeconomic development as an intervention against malaria: a systematic review and meta-analysis. Lancet 2013; 382:963-972.

21. Wu SH, Woo J, Zhang X-H. Worldwide socioeconomic status and stroke mortality: an ecological study. Int J Equity Health 2013; 12:42.

22. Vecina Neto G, Malik AM. Tendências na assistência hospitalar. Cienc Saude Coletiva 2007; 12:825-839.

23. Rasella D, Aquino R, Barreto ML. Impact of income inequality on life expectancy in a highly unequal developing country: the case of Brazil. J Epidemiol Community 2013; (Internet). (Accessed 2014 September). Available at: http://jech.bmj.com/content/ early/2013/04/30/jech-2012-201426.short

24. Teixeira TRA, Cruz OG. Spatial modeling of dengue and socioenvironmental indicators in the city of Rio de Janeiro, Brazil. Cad Saude Publica 2011; 27:591-602.

25. Flauzino RF, Souza-Santos R, Oliveira RM. Dengue, geoprocessing, and socioeconomic and environmental indicators: a review. Rev Panam Salud Publica 2009; 25:456-461.

26. Siegel M, Luengen $M$, Stock S. On age-specific variations in income-related inequalities in diabetes, hypertension and obesity. Int J Public Health 2013; 58:33-41.

27. Da Cunha SS, Pujades-Rodriguez M, Barreto ML, Genser B, Rodrigues LC Ecological study of socio-economic indicators and prevalence of asthma in schoolchildren in urban Brazil. BMC Public Health 2007; 7:205-211.

28. Guzmán MG, Alvarez M, Rodriguez R, Rosario D, Vásques S, Vald L, et al. Fatal dengue hemorrhagic fever in Cuba, 1997. Int J Infect Dis 1999; 3:130-135.

29. Leo YS, Thein T, Fisher DA, Low JG, Oh HM, Narayanan RL, et al. Confirmed adult dengue deaths in Singapore: 5-year multicenter retrospective study. BMC Infect Dis 2011; 11:123.

30. Figueiredo MAA, Rodrigues LC, Barreto ML, Lima JWO, Costa MCN, Morato V, et al. Allergies and diabetes as risk factors for dengue hemorrhagic fever: results of a case control study. PLoS Negl Trop Dis 2010; 4:1-6.

31. Moraes GH, Duarte EC. Análise da concordância dos dados de mortalidade por dengue em dois sistemas nacionais de informação em saúde, Brasil, 2000-2005. Cad Saude Publica 2005; 25: 2354-2364.

32. Teixeira MG, Costa MCN, Barreto F, Barreto ML. Dengue: twenty-five years since reemergence in Brazil. Cad Saude Publica 2009; 25:7-18. 